\title{
New species of Microhyla from Sarawak: Old World's smallest frogs crawl out of miniature pitcher plants on Borneo (Amphibia: Anura: Microhylidae)
}

\author{
INDRANEIL DAS ${ }^{1,3} \&$ ALEXANDER HAAS ${ }^{2}$ \\ ${ }^{\prime}$ Institute of Biodiversity and Environmental Conservation, Universiti Malaysia Sarawak, 94300, Kota Samarahan, Sarawak, \\ Malaysia.E-mail: idas@ibec.unimas.my \\ ${ }^{2}$ Biozentrum Grindel und Zoologisches Museum, Martin-Luther-King-Platz 3, 20146 Hamburg, Germany. \\ E-mail: alexander.haas@uni-hamburg.de \\ ${ }^{3}$ Corresponding author
}

\begin{abstract}
A new diminutive species of microhylid frog (genus Microhyla) is described from the Matang Range, Sarawak, Malaysian Borneo. The new species is an obligate of the pitcher plant, Nepenthes ampullaria, breeding in senescent or mature pitchers, and is Old World's smallest frog and one of the world's tiniest: adult males range between SVL 10.6$12.8 \mathrm{~mm}(n=8)$. The new species is diagnosable from congeners in showing dorsum with low tubercles that are relatively more distinct on flanks; a weak, broken, mid-vertebral ridge, starting from forehead and continuing along body; no dermal fold across forehead; tympanic membrane and tympanic annulus absent; Finger I reduced to a nub proximal to Finger II in males; toe tips weakly dilated; phalanges with longitudinal grooves, forming two scale-like structures; webbing on toe IV basal; toes with narrow dermal fringes; inner and outer metatarsal tubercles present; and dorsum brown with an hour-glass shaped mark on scapular region. Miniaturization and reduced webbing may be the result of navigation on the slippery zone of pitchers, situated below the peristome.
\end{abstract}

Key words: Microhyla nepenthicola sp. nov., Microhylidae, Kubah National Park, Sarawak, Borneo

\section{Introduction}

A number of amphibian species that are under $15 \mathrm{~mm}$ have been termed 'diminutive', 'minute', or 'miniature' (Estrada and Hedges 1996; Biju et al. 2007; Duellman and Hedges 2008). The smallest amphibian species known belong to the genera Eleutherodactylus (fide Estrada and Hedges 1996), Brachycephalus (fide Frost et al. 2006), Noblella (fide Lehr and Catenazzi 2009), and Stumpffia (fide Vences and Glaw 1991). Among Old World frogs, the smallest member of the microhylid genus Stumpffia of Madagascar, S. pygmaea, has an adult SVL range 10.9-12.0 mm (Vences and Glaw 1991). Lehr and Catenazzi (2009) discussed the potential problems with the use of the term "smallest" for anuran amphibian adults, including the necessity of large series of specimens to understand body size variation, and some reports may suffer from sex-based sampling bias. Nonetheless, miniaturization itself is a biologically intriguing phenomenon and offer substantial opportunities for further biological investigations into development and ontogenetic aspects, field biology and other aspects.

The genus Microhyla Tschudi, 1838 (Anura: Microhylidae) is a relatively speciose, with 30 species currently recognized (Frost 2009), its members known from the Indian subcontinent, Indo-Malaya and IndoChina (Frost 1985; Iskandar and Colijn 2000; Matsui et al. 2005). Five nominal species have been reported from Borneo: Microhyla berdmorei (Blyth 1856); M. borneensis Parker 1928; M. maculifera Inger 1989; M. perparva Inger and Frogner 1979, and M. petrigena Inger and Frogner 1979.

During studies of amphibians, focused on identification of their larval forms to parent species using genetic barcoding, we collected a series of Microhyla from Kubah National Park, Matang Range, Sarawak, Malaysia (western Borneo; Fig. 1), which do not fit the description of a known species. 